\title{
Imágenes sobre dinosaurios en libros de texto de Enseñanza Secundaria Obligatoria*
} Images on dinosaurs in textbooks of Secondary

\author{
Luis Mampel ${ }^{(1)}$ \\ Ángel Luis Cortés Gracia ${ }^{(2)}$ \\ Luis Alcalá (1)
}

(1) Museo Aragonés de Paleontología (Fundación Conjunto Paleontológico de Teruel-Dinópolis)

(2) Dpto. de Didáctica de las Ciencias Experimentales. Universidad de Zaragoza

Resumen: El concepto "dinosaurio" no forma parte explícita del saber a enseñar en los curricula oficiales de ESO dentro del periodo LOGSE-LOE español (1990-2010). A pesar de ello, algunos autores y editoriales decidieron incluirlo como objeto de enseñanza en los libros de texto. El análisis de estos libros revela una abundante presencia de información gráfica, con un predominio de imágenes desprovistas de rasgos que identifiquen los elementos representados así como la presencia ocasional de modelos alternativos y un déficit en la concurrencia entre textos e imágenes que reduce su potencial didáctico.

Palabras clave: dinosaurios, imágenes, libros de texto, Educación Secundaria, ideas alternativas.

Abstract: The "dinosaur" concept is not an explicit part of the knowledge to be taught in the official curriculum of Secondary Education within the Spanish LOGSE-LOE (1990-2010). However, some authors and publishers decided to include it as an object of teaching in the textbooks. The analysis reveals an abundance of graphic information, with a predominance of images devoid of features that identify the elements represented, the occasional presence of alternative models and a deficit in the competition between texts and images that reduces their educational potential.

Key Words: dinosaur, images, textbooks, secondary school, misconception.

(Fecha de recepción: noviembre, 2014, y de aceptación: mayo, 2015)

DOI: 10.7203/DCES.29.4312

\footnotetext{
* Agradecimientos: Proyecto DINOTUR CGL2013-41295-P (Ministerio de Economía y Competitividad), Grupo de Investigación Consolidado E-62 FOCONTUR (Dep. de Industria e Innovación, Gobierno de Aragón y Fondo Social Europeo) e Instituto Aragonés de Fomento. Grupo de Investigación "Beagle" (UNIZAR) y Proyecto EDU2011-27098 (MEC). Al editor de la revista y a los dos revisores anónimos por sus comentarios y sugerencias.
} 


\section{Introducción}

Los libros de texto de ciencias empleados en la Enseñanza Secundaria Obligatoria (ESO) -y por ende los de Ciencias de la Naturaleza y Biología y Geología-, son un recurso educativo tradicionalmente empleado por los docentes que ha conseguido captar la atención de un gran número de investigaciones debido a su importante papel en los procesos de enseñanza-aprendizaje (Perales y Vílchez-González, 2012). Junto a las noticias científicas en la prensa diaria, cuyo potencial didáctico en la enseñanza de la ciencia es destacado (García-Carmona, 2014), destaca el papel de los libros de texto siendo ambos medios escritos los más relevantes a la hora de comunicar ciencia y tecnología a un público no especializado (Dimopoulos et al., 2003).

Tanto los libros de Educación Primaria (EP) como Secundaria presentan una importante cantidad de información visual, más aún si cabe durante las últimas décadas, donde han adquirido una presencia muy destacada. Así lo constatan diversos análisis realizados sobre libros de texto donde las imágenes representan -e incluso llegan a superar-, el 50\% de espacio impreso (Jiménez y Perales, 2001; Perales y Jiménez, 2002; Perales, 2008). Tal importancia es debida a que, tradicionalmente, se asigna a las imágenes -junto a otros medios audiovisuales- varias funciones, entre ellas, el beneficio de suscitar nuevos estímulos para el aprendizaje y promover la comprensión de conceptos y modelos (Reid, 1990a).

Levie y Lentz (1982) señalaban que aquellos textos acompañados de ilustraciones, mostrando y complementando el mensaje del texto, permitían un mejor aprendizaje entre los alumnos que aquellos textos que carecían del soporte de imágenes. No obstante autores como Jiménez y Perales (2001), Perales y Jiménez (2004), Matus et al., (2008) o Cook, (2008) justifican el elevado número de imágenes en libros de texto como simples estrategias de mercadotecnia editorial. Otra razón atribuida para justificar el incremento proporcional de imágenes en los libros de texto durante los últimos años -respecto a décadas anteriores-, es el desarrollo de nuevas tecnologías que facilitan la creación e inclusión de imágenes en el proceso de edición (Dimopoulos et al., 2003; Perales y Jiménez, 2002).

En cualquier caso, parece que la abundancia (o sobreabundancia) de imágenes no facilita forzosamente la comprensión de los conceptos que ilustran (Perales y Jiménez, 2002), ni siquiera la motivación hacia su estudio cuestionando su propia función como fuente de aprendizaje (Mottet, 1996). Así las ilustraciones desvinculadas del texto no aportan una mejora en el proceso de enseñanza-aprendizaje de los alumnos (Levie y Lentz, 1982) y aunque son fundamentales para la comunicación de ideas en las clases de ciencias, el diseño de éstas no es siempre el mejor y más beneficioso (Cook, 2006). 
A pesar del progresivo incremento de imágenes en libros de texto existe una escasez de referencias bibliográficas relativas al uso de las estrategias basadas en el trabajo con imágenes para la enseñanza-aprendizaje de la ciencia (Perales, 2006; Silva y Compiani, 2006), aún más patente en disciplinas como la paleontología (a pesar de contar con conceptos científicos tan populares como los "dinosaurios").

Este hecho no es de extrañar dado que durante el periodo 1990-2010, los sistemas educativos españoles LOGSE (Ley Orgánica General del Sistema Educativo) y LOE (Ley Orgánica de Educación) no establecieron contenidos sobre paleontología general entre los criterios de enseñanza mínimos de Educación Primaria (Torcida, 2003; Romero Nieto et al., 2014) ganando presencia en los currículos de Enseñanza Secundaria. Así, la paleontología sensu estricto comienza a impartirse en ESO como un tema de la asignatura obligatoria de Biología y Geología de $1^{\circ}$ de ESO. En el resto de cursos, así como durante el Bachillerato, es tratada en asignaturas optativas o de modalidad (Romero et al., 2014). Las asignaturas "Ciencias de la Naturaleza" y "Biología y Geología" (dentro de la ESO) recogían algunos contenidos generales sobre Paleontología (Gil-Bazán, 2009) donde los dinosaurios podían tener cabida en bloques como: a) Los seres vivos y su diversidad: la vida a lo largo de la historia terrestre. Los fósiles ( $1^{\circ} \mathrm{ESO}$ ); b) La Tierra, un planeta en continuo cambio $\left.\left(4^{\circ} \mathrm{ESO}\right), \mathrm{c}\right)$ La evolución de la vida (4 ${ }^{\circ}$
ESO) o d) Las transformaciones en los ecosistemas ( $4^{\circ} \mathrm{ESO}$ ).

En este contexto se efectuó un primer diagnóstico de los contenidos textuales sobre dinosaurios en una muestra de 177 libros de texto (72 de EP y 105 de ESO) en el periodo de publicación 19902010 (Mampel y Cortés, 2012).

En EP se detectó la ausencia del concepto vinculada a la materia "Conocimiento del Medio" (Mampel y Cortés, 2012) extendida a 'práctica ausencia' tras sumar a la primera muestra dos honrosas excepciones: Gómez y Valbuena, 2008 y Gómez et al., 2007. En ESO se detectaron contenidos paleontológicos sobre dinosaurios en 42 ( $1^{\circ} \mathrm{ESO}$ : 15 ; $2^{\circ}$ ESO: 4 y $4^{\circ}$ ESO: 23) de los 105 libros analizados donde son tratados, de diversas formas, dentro de tres grandes contextos genéricos en los que aparece el concepto (definidos en Mampel y Cortés, 2012): A) en el marco de las extinciones y/o catástrofes, B) de forma descriptiva dentro de la historia de la Tierra y la Vida y C) con carácter anecdótico.

Partiendo del análisis previo del contenido textual (Mampel y Cortés, 2012) surgió la inquietud por describir, analizar e interpretar la iconografía existente sobre el concepto "dinosaurio" en la misma selección de libros de texto de ESO de la etapa LOGSE-LOE (1990-2010) que presentan contenidos sobre el concepto dinosaurio, con el fin de conocer qué papel didáctico desempeñan, su interrelación con el contenido textual y cómo contribuyen a la representación del concepto. 


\section{Marco teórico}

\section{Imágenes y aprendizaje}

El concepto de transposición didáctica, propuesto por Verret en 1975, fue retomado posteriormente por Chevallard (1985) quien centró su estudio en saber cómo el conocimiento científico (saber experto o saber sabio) se transforma, a través del proceso de extracción del cuerpo de contenidos que constituye el saber a enseñar, hasta llegar a las aulas de enseñanza obligatoria (como objeto de enseñanza) mediante su transposición, experimentando adecuaciones particulares que configuran cierta pérdida de la historia y del contexto del descubrimiento o invención (Bermudez et al., 2014). Los libros de texto son el producto de dicha transposición y, como objetos culturales, son el reflejo de la expresión de sus autores en un momento histórico y un contexto social determinado con el fin de hacer posibles las prácticas en el aula donde profesores y estudiantes participan (Izquierdo et al., 2008).

Por otra parte, el enfoque constructivista del aprendizaje plantea la construcción de significados como un proceso activo de relación entre nuestras ideas existentes y las nuevas. En este proceso de aprendizaje significativo cada persona desempeña un papel relevante y personal, encargándose de dar sentido a los hechos a los que se enfrenta construyendo representaciones mentales que se acomodan a los esquemas de creencias y conocimientos ya existentes. Según este enfoque, la percepción de una imagen no es la percepción de la realidad e implica igualmente un proceso de construcción a través de ella (Gil Quílez y Martínez Peña, 2005) por parte del observador (quien se encarga de dotarles de significado; De Dios et al., 1997) de forma personal (Fanaro et al., 2005). Pero el conocimiento no se produce como consecuencia de la simple percepción de una imagen y depende del significado atribuido por el observador, que es quien realiza la construcción activa de significados de forma constante a la vez que interacciona con su ambiente.

Por tanto las personas interpretamos las imágenes en función de, entre otras, las necesidades de información, estrategias de procesamiento, conocimientos previos, capacidad y determinación (Matus et al., 2008). Para lograr este cometido son necesarios aspectos como: a) una perfecta articulación entre la información gráfica y verbal en los libros (Paivio, 1986; Anglin et al., 2004); b) el desarrollo de unas condiciones didácticas y cognitivas que permitan la transformación imagen-conocimiento (Mottet, 1996) y c) el desarrollo de habilidades que permitan "leer" (decodificar) de forma eficiente la información contenida en las imágenes (Reid, 1990a y 1990b; Gil y Martínez, 2005).

Hay evidencias significativas que ponen de manifiesto que, de modo general, la memoria y el recuerdo para las imágenes es mejor que la memoria para las palabras (Paivio, 1975 citado en Najjar, 1995). A este hecho se le denomina Efecto de Superioridad de las Imágenes (Picture Superiority Effect) y 
existen tres perspectivas teóricas generales que tratan de explicarlo (Anglin et al., 2004): a) Teoría de doble codificación (dual-code model), b) Teoría de codificación simple (single-code model) y c) modelo sensorial semántico (sensorysemantyc model).

El modelo de doble codificación es el referente ampliamente más aceptado y citado (Perales, 2006) e intenta explicar el procesamiento de las imágenes mediante una doble vía, una no verbal y otra verbal para el texto (en el caso de libros de texto escrito) no independientes entre sí (Perales 2006, Cook,
2006). Los defensores de la teoría de la codificación simple argumentan que la información visual es transformada en proposiciones abstractas almacenadas en la memoria semántica de manera que las imágenes activan un sistema de memoria semántico autónomo diferente del que activan las palabras. Y por último, el modelo sensorial-semántico defiende que puede haber un código sensorial más distintivo para las figuras que hace que el proceso semántico (la probabilidad de que las figuras sean procesadas semánticamente) sea mayor que para las palabras (Figura 1).

\section{Figura I}

\section{Aprendizaje a partir del ordenamiento de imágenes y palabras}

\section{Teoría de doble codificación Teoría de codificación simple Modelo sensorial semántico}
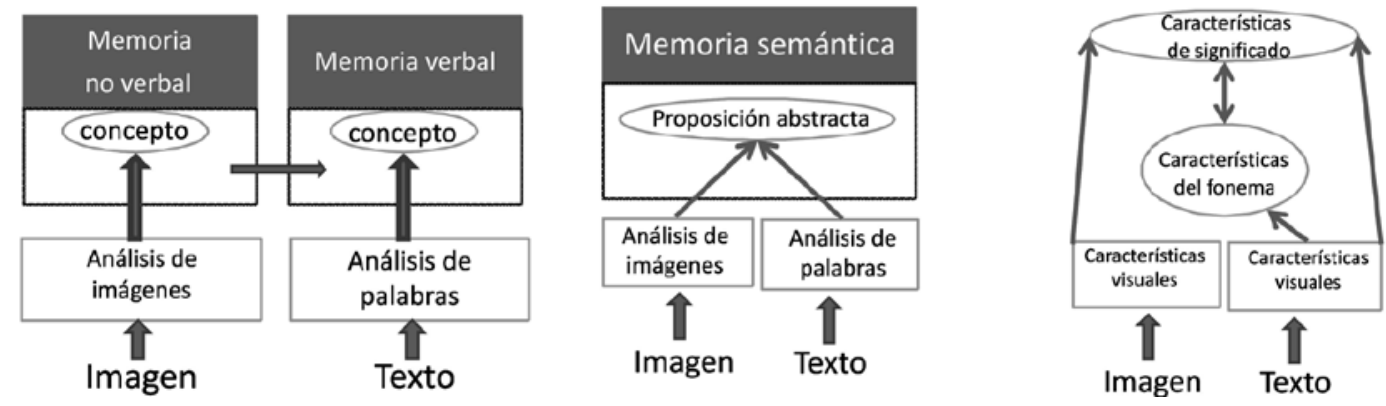

Fuente: Anglin et al., (2004).

De acuerdo con la teoría de la doble codificación, el aprendizaje a través de imágenes combinadas con textos relacionados es más rico que el aprendizaje a partir de textos sin imágenes o a través de imágenes aisladas (Levie y Lentz, 1982; Najjar, 1995). Así, el uso de ciertas imágenes capaces de motivar a que el observador tenga un papel activo en los procesos de recepción, selección, transformación, almacenamiento y recuperación de la información puede facilitar el proceso de aprendizaje. En otras ocasiones, las imágenes constituyen un 
elemento atractivo que puede tener un efecto mnemotécnico o simplemente gratificante dentro de unos contenidos complejos y/o poco atractivos (Pardo y Rebollo, 2008). En definitiva las ilustraciones pueden ayudar a comprender el texto ilustrado, facilitando su memorización, especialmente a largo plazo, y permiten una gran variedad de funciones instructivas (Levie y Lenz, 1982).

\section{Las imágenes sobre dinosaurios en el aula}

A veces las imágenes constituyen el único referente accesible para los estudiantes en las aulas, representando un elemento imprescindible y esencial de la ciencia en general y de ciertas disciplinas (Perales, 2006 y 2008) como la Geología (una ciencia excepcionalmente visual; Reynolds et al., 2005) o la Biología de forma particular. La Paleontología posee un carácter interdisciplinario entre Ciencias de la Tierra y Ciencias de la Vida y tiene, entre sus objetivos más ambiciosos, desentrañar la Historia de la Vida desde todas sus vertientes (Alcalá, 2005).

Cualquier intento de enseñanza de paleontología de vertebrados en el aula (dinosaurios, evolución humana...), exige -de forma casi necesaria-, el uso de imágenes como recurso. Tradicionalmente, algunos Institutos de Enseñanza Secundaria cuentan con colecciones paleontológicas que pueden servir como recurso didáctico para la enseñanzaaprendizaje de la paleontología pero, en muchas ocasiones, se trata de colec- ciones compuestas, casi de forma exclusiva, por fósiles de invertebrados. Como opción algunos centros educativos planifican visitas a museos y centros de ciencia, que suelen albergar colecciones con fósiles de vertebrados en su exposición permanente.

Con el uso de las tecnologías de la información e Internet también es posible tener acceso a imágenes (estáticas y dinámicas) e información textual sobre dinosaurios. La informatización de las colecciones patrimoniales, a través de distintas vías, permite gestionar colecciones de contenido paleontológico posibilitando su consulta en red a través de distintas fuentes. De esta forma se pone a disposición de profesores y alumnos (y por supuesto de toda la sociedad) información de calidad de forma libre y gratuita, conformando un sugestivo recurso didáctico con potencial para la enseñanza de las ciencias y ampliando, además, el potencial educativo del Museo que permite la difusión del conocimiento hacia muchos grupos de usuarios (Mampel et al., 2011).

Pero sin salir del aula, una de las pocas oportunidades de interaccionar con imágenes sobre dinosaurios (exceptuando el uso de las tecnologías de la información y comunicación) se restringe al uso de aquellas incorporadas en los libros de texto. En textos de la LOGSE Calvo y Gil Bazán (1997) detectaron un tipo de imágenes afines y frecuentes en el campo de la paleontología, las reconstrucciones paleoecológicas.

Una reconstrucción paleoecológica es una "herramienta" paleontológica 
que permite proponer un modelo complejo, con gran cantidad de información (procedente de distintas disciplinas científicas), con el fin de reconstruir los ecosistemas de la Tierra a lo largo del tiempo geológico. Una reconstrucción de este tipo cuenta con un plano real constituido por: los fósiles recuperados (tanto restos directos como indirectos, estudio sistemático, filogenético...), las estructuras sedimentarias relacionadas y la disposición espacial de los distintos elementos fósiles recuperados en un yacimiento que, junto al estudio paleobiológico y paleobiogeográfico, permiten la reconstrucción de los ecosistemas antiguos.

El plano teórico se encuentra principalmente dentro del campo de la paleontología, apoyado en subdisciplinas como la taxonomía o la tafonomía y sustentado sobre los pilares de la Geología y la Biología, a través de disciplinas como son la estratigrafía, sedimentología o paleoecología, entre otras fuentes de información complementaria.

El estudio de los ecosistemas antiguos se complementa con las reconstrucciones paleobiológicas de los taxones del pasado, partiendo del estudio e interpretación de los fósiles. En las representaciones de ecosistemas antiguos -en especial para sistemas mesozoicos terrestres durante los periodos Jurásico y Cretácico-, es previsible esperar una asociación faunística compuesta por, entre otros animales, dinosaurios. Calvo y Gil Bazán (1997) consideran -tras realizar un análisis del tratamiento en libros de texto de las reconstrucciones paleo- ecológicas- que, en general, es mínima la información ofrecida sobre los procesos a seguir en una reconstrucción de este tipo (soslayando los aspectos procedimentales que conducen a la realización de un modelo sobre la vida del pasado).

La modelización es una de las herramientas básicas en la construcción de la Ciencia (y su enseñanza) que sirve para la elaboración de descripciones, explicaciones y predicciones sobre la Naturaleza de manera que permita su intercambio y el debate dentro de la comunidad científica. Se ha de procurar siempre, especialmente en el caso de la enseñanza de esos modelos, establecer una clara separación entre la realidad que se pretende representar, la teoría elaborada para explicarla y los símbolos elegidos para hacerlo (Perales, 2008). $\mathrm{Si}$ consideramos las reconstrucciones paleoecológicas como modelos simbólicos de los ecosistemas del pasado, su principal función es constituir un medio de representación del conocimiento a través del proceso de modelización (Perales, 2008), por lo que debiera potenciarse su uso teniendo presente una clara separación entre los planos real, teórico y simbólico que, en el caso de las reconstrucciones paleoecológicas, parece no hacerse efectiva.

En estas reconstrucciones influye el enfoque y la tecnología empleada por el "paleoartista" (en la mayoría de ocasiones asesorado por científicos o diseñado por ellos mismos), quien dotará de morfología, posición anatómica y colores personalizados (siguiendo normalmente criterios actualistas) y pondrá en escena 
los distintos actores que formen parte de la paleobiocenosis y el propio paleobiotopo, que de forma conjunta, constituirán la recontrucción del paleoecosistema.

Uno de los valores fundamentales de las imágenes que acompañan al texto escrito estriba en su capacidad para trasmitir una información que sería más difícil de entender si fuera explicada de otro modo e, incluso, que no pudiera presentarse de ninguna otra forma (Pérez de Eulate et al., 1999). En el caso concreto de las reconstrucciones paleoecológicas, pueden albergar gran cantidad de información científica "oculta" pendiente de ser vista, leída e interpretada. Un libro de texto puede incluir información textual sobre las características de los dinosaurios, junto a otros animales coetáneos (paleoambiente, el resto de fauna y flora que convivió con ellos, etc.) pero la inclusión de una reconstrucción paleoecológica reúne gran cantidad de información, aportando matices sobre locomoción, posturas, hábitos, comportamiento... difícil de explicar de forma verbal.

\section{Metodología de la investigación}

La metodología de investigación se centra en el análisis de 42 libros de texto de ESO de la etapa LOGSE-LOE del periodo 1990-2010 seleccionados a raíz de un diagnóstico previo (Mampel y Cortés, 2012) por el hecho de contener información textual sobre el concepto "dinosaurio". Los libros pertenecen a las siguientes editoriales: Akal, Algaida, Almadraba, Anaya, Bruño, Casals,
Edebé, Ecir, Editex, Everest, McGraw Hill, Santillana, SM y Vicens Vives y están distribuidos entre $1^{\circ}(\mathrm{n}=15), 2^{\circ}$ $(n=4)$ y $4^{\circ} \operatorname{ESO}(n=23)$.

Se procedió a la localización, revisión y análisis del total de las imágenes detectadas considerando la taxonomía y bases teóricas propuestas por Perales y Jiménez (2002). Dichas bases consisten en un sistema de categorías empíricas que permite clasificar y evaluar la adecuación de las ilustraciones sobre el concepto dinosaurio en los libros de ciencias.

En el presente trabajo se consideró la función didáctica de las imágenes (bien sean fotografías, modelos -reconstrucciones paleoecológicas y paleobiológicas-, mapas, esquemas o diagramas) vinculadas con el concepto "dinosaurio" valorando: a) grado de iconicidad, b) relación con el texto principal, c) etiquetas verbales y d) contenido científico.

\section{Grado de iconicidad}

El grado de iconicidad establece un rango creciente de simbolización (Perales y Jiménez, 2002) o grado de semejanza visual entre la imagen y el objeto que representa (Pérez de Eulate et al., 1999). La iconicidad es el concepto opuesto a la abstracción de modo que cuanto más abstracta es una imagen menos icónica resulta (Matus et al., 2008).

Perales y Jiménez (2002) proponen distintas categorías para clasificar el grado de iconicidad en las imágenes (basándose en la escala original propuesta por Moles, 1991). El mayor grado de ico- 
nicidad, tras las fotografías, corresponde a la categoría dibujo figurativo (se trata de una imagen donde prima la representación orgánica, mostrando los objetos mediante imitación de la realidad). Una reconstrucción paleoecológica es un modelo cuyo resultado pretende ser la representación de una realidad inferida a través del estudio científico (anatomía, taxones, ambientes...).

Las reconstrucciones paleoecológicas se han ido transformando conforme se ha incrementado el conocimiento sobre el concepto, desde las primeras efectuadas durante el siglo XIX. Desde entonces, se caracterizan por poseer un alto grado de iconicidad y, aunque no pueden ser clasificadas en sentido estricto entre ninguna de las categorías propuestas por Perales y Jiménez (2002), en sentido laxo serán clasificadas como dibujos figurativos. Por tanto este tipo de reconstrucciones son una interpretación (modelo) flexible y cambiante sobre el cual no hay certeza absoluta de que sea el reflejo exacto de la realidad (conforme evolucionan los referentes científicos pueden sufrir modificaciones notables), a pesar de que, el aspecto final, en ocasiones es -o pretenda ser- realista.

\section{Relación con el texto principal}

Comprende el estudio de todas aquellas referencias mutuas establecidas entre texto e imagen. Perales y Jiménez (2002) realizan una clasificación dependiendo del tipo de relación establecida por los autores de los libros entre el texto y las imágenes. Los autores diferencian tres categorías equivalentes a las descritas, con otra terminología, por Otero et al., 2003:

1) Connotativa (equivalente a la categoría Asociativa propuesta por Otero et al., 2003): el texto describe los contenidos sin mencionar su correspondencia con los elementos incluidos en la ilustración donde las relaciones se suponen obvias y las establece el lector. Por tanto se establecen muy pocas referencias entre la imagen y el texto.

2) Denotativa (categoría propuesta con el mismo nombre por Otero et $a l ., 2003)$ : el texto establece la correspondencia entre los elementos de la ilustración y los contenidos representados.

3) Sinóptica (equivalente a la categoría Interactiva propuesta por Otero et al., 2003): el texto describe la correspondencia entre los elementos de la ilustración y los contenidos representados, y establece, además, las condiciones en las cuales las relaciones entre los elementos incluidos en la ilustración representan las relaciones entre los contenidos, de modo que imagen y texto forman una unidad indivisible.

\section{Etiquetas verbales}

Las etiquetas verbales (Perales, 2006) son textos que -a modo de mensaje textual ya sea superpuesto o de modo 
adjunto como un pie de figura- acompañan a una imagen apoyando su interpretación (Perales y Jiménez, 2002).

Las etiquetas verbales (rótulos en términos de Pérez de Eulate et al., 1999) tienen diversos fines, como seleccionar la información relevante presente en el texto o en la imagen, poner de manifiesto la relación causa-efecto sobre un proceso o establecer relaciones entre diferente partes de una imagen. Según los mismos autores, la interacción entre el texto explicativo y la imagen no depende exclusivamente de la proximidad en la página sino también de la presencia de anotaciones verbales (rótulos). Las investigaciones indican que los efectos positivos de la integración texto-imagen en la comprensión de conceptos científicos dependen, más que de la proximidad espacial entre dichos factores, de la incorporación de anotaciones en las ilustraciones (Mayer et al., 1995).

Las categorías propuestas por Perales y Jiménez (2002) y empleadas en este trabajo son: a) Sin etiquetas (las ilustraciones no contienen ningún texto); b) Nominativas (la imagen contiene letras, palabras y/o textos breves que identifican algunos elementos de la ilustración) y, c) Relacionales (las imágenes poseen textos que describen las relaciones entre los elementos de la ilustración).

\section{Contenido científico}

Existe una amplia evidencia experimental que demuestra que los alum- nos y, en ocasiones, los profesores tienen ideas equivocadas sobre la ciencia y el conocimiento científico. Lo mismo sucede, con frecuencia, con el objeto de enseñanza que presentan los libros de texto $y$, si bien se puede atribuir a los contenidos de los libros de texto un conocimiento científico certificado y correcto, no hay que descartar la presencia de errores conceptuales no intencionados (Campanario, 2001). Este campo pretende valorar si el tratamiento del concepto "dinosaurio" vinculado a las imágenes en los libros de texto presenta incorrecciones o ideas alternativas.

En este apartado también se analiza la relación existente entre las imágenes y la información textual sobre el concepto "dinosaurio" presente en los libros según tres grandes categorías (Mampel y Cortés, 2012):

Los libros con una tipología $\mathbf{A}$ $(\mathrm{n}=14)$ presentan la información en el marco de las extinciones y/o catástrofes, aunque no definen el concepto y centran su discurso principalmente en las distintas hipótesis y teorías acerca de la extinción de los dinosaurios.

Los libros de texto con una tipología $\mathbf{B}(\mathrm{n}=17)$ tienen un punto de vista descriptivo-explicativo (dentro de la Historia de la Tierra y de la Vida), aunque definen el concepto "dinosaurio" tratando unos mínimos necesarios para tener una visión general.

Finalmente, la tercera categoría de libros (C) $(\mathrm{n}=11)$ muestra el concepto con un carácter anecdótico y realiza una definición sesgada del concepto sin estar centrado su discurso, de forma ex- 
clusiva, en la causa de la extinción de los dinosaurios.

\section{Resultados y discusión}

Como primer dato cabe señalar la localización de 134 imágenes sobre dinosaurios en 38 de los 42 libros de texto analizados. Este dato pone de manifiesto su notable presencia, de forma especial en $4^{\circ}$ de ESO donde se encontró una media superior a cuatro imágenes por libro. Sólo en cuatro ejemplares -con información textual sobre el concepto- no se encontraron imágenes relacionadas (Cuadro I).

Sobre la distribución del tipo de imagen (Cuadro II), la categoría "Fotografías" es la más frecuente representando el 44\% del total, seguido de las "Reconstrucciones paleobiológicas" aisladas (es decir no englobadas dentro del contexto de una reconstrucción paleoecológica) con un porcentaje de $26,1 \%$, y las "Reconstrucciones paleoecológicas" $(21,6 \%)$. En la categoría "Otros" $(8,3 \%)$ se incluyen, entre otros, representacio-

\section{Cuadro I}

Distribución del número de imágenes de dinosaurios por curso académico e índice del número de imágenes por libro sobre el total de textos analizados

\begin{tabular}{lccc}
\hline Concepto ‘dinosaurio’ & $\mathbf{1}^{\mathbf{o}}$ ESO $(\mathbf{n = 1 5})$ & $\mathbf{2}^{\mathbf{o}}$ ESO $(\mathbf{n = 4})$ & $\mathbf{4}^{\mathbf{o}}$ ESO $(\mathbf{n = 2 3})$ \\
\hline Número de imágenes & 29 & 5 & 100 \\
\hline $\mathrm{n}$ (libros con imágenes) & $12(80 \%)$ & $4(100 \%)$ & $22(95,5 \%)$ \\
\hline $\mathrm{n}$ (libros sin imágenes) & $3(20 \%)$ & 0 & $1(4,5 \%)$ \\
\hline${\text { Índice } \mathrm{n}^{\circ} \text { imágenes/libro }}$ & 1,9 & 1,2 & 4,3 \\
\hline
\end{tabular}

Fuente: Elaboración propia

\section{Cuadro II}

Distribución del número de imágenes de dinosaurios entre las categorías más abundantes

\begin{tabular}{cccc} 
Fotografías & $\begin{array}{c}\text { Reconstrucciones } \\
\text { paleobiológica }\end{array}$ & $\begin{array}{c}\text { Reconstrucciones } \\
\text { paleoecológica }\end{array}$ & Otros \\
\hline
\end{tabular}

Número

de imágenes

$59(44,0 \%)$

$35(26,1 \%)$

$29(21,6 \%)$

$11(8,3 \%)$

Fuente: Elaboración propia 


\section{Cuadro III}

Distribución del número de fotografías $(\mathrm{n}=59)$ sobre dinosaurios

\begin{tabular}{lccccc}
\hline & $\begin{array}{c}\text { Fósiles (Restos } \\
\text { directos: huesos) }\end{array}$ & $\begin{array}{c}\text { Fósiles (Restos } \\
\text { indirectos: Icnitas) }\end{array}$ & $\begin{array}{c}\text { Corpóreos } \\
\text { dinosaurios }\end{array}$ & $\begin{array}{c}\text { Fósiles } \text { (Restos } \\
\text { indirectos: huevos) }\end{array}$ & Otros \\
\hline Fotografías & 32 & 15 & 7 & 3 & 2 \\
\hline
\end{tabular}

Fuente: Elaboración propia

nes o esquemas del esqueleto de dinosaurios o sus icnitas.

Los contenidos representados con mayor frecuencia dentro de la categoría "Fotografías" (Cuadro III) son fósiles con restos directos de dinosaurios $(n=32)$ : cráneos y/o esqueletos completos. Seguidamente, fósiles con restos indirectos (icnitas -huellas de dinosaurios-) ( $\mathrm{n}=15)$, imágenes de corpóreos de dinosaurios (fotografías de modelados y/o maquetas) $(\mathrm{n}=7)$ y fósiles con otros restos indirectos, como huevos $(n=3)$.

\section{El grado de iconicidad}

El grado de iconicidad presente en el conjunto de las imágenes analizadas es alto. Las fotografías -elementos más reales y menos abstractos- son las imágenes más frecuentes. A continuación encontramos representaciones paleobiológicas y paleoecológicas -con un alto grado de iconicidad, aunque menor que el de las fotografías- constituyendo, entre ambas, casi la mitad de las imágenes $(47,7 \%)$. El 8,3\% restante incluye imágenes con diverso grado de iconicidad (dibujos figurativos con signos principalmente). El resultado de sumar los porcentajes alcanzados por fotogra- fías y representaciones paleoecológicas/ paleobiológicas supera el $90 \%$ del total de las imágenes.

En un análisis propuesto por Perales y Jiménez (2002) para imágenes sobre mecánica en libros de ESO, se alcanzó un valor del $70 \%$ para el sumatorio de las imágenes con mayor grado de iconicidad (menor incluso que en el presente análisis). Estos autores argumentan que la utilización masiva de fotografías en los libros de texto (así como dibujos figurativos) no mejora necesariamente la comprensión de los textos, por lo que la razón de su inclusión puede ser -aparte de la propia evolución técnica del proceso de impresión-, la creencia (por parte de las editoriales) de que las imágenes atraen a los lectores (Perales y Jiménez, 2002) y de que ayudan en el proceso de enseñanza-aprendizaje.

\section{Relación con el texto principal}

En cuanto al número de imágenes detectadas, por categorías establecidas para la relación entre texto principal e imágenes, se observa un predominio de las imágenes connotativas (Cuadro IV) donde las relaciones se suponen obvias y las establece el lector. 
Cuadro IV

Distribución del número de imágenes sobre dinosaurios según su relación con el texto principal

\begin{tabular}{lccc}
\hline & Connotativa & Denotativa & Sinóptica \\
\hline Número de imágenes & 111 & 19 & 4 \\
\hline
\end{tabular}

Fuente: Elaboración propia

Etiquetas verbales

Sobre el tipo de etiqueta verbal vinculado a las imágenes analizadas existe un predominio de etiquetas nominativas, es decir, aquellas que con letras o palabras identifican algunos elementos de la imagen (Cuadro V). Este dato es muy similar al encontrado en el análisis de imágenes asociadas a otros campos científicos como el enlace químico (Matus et al., 2008).

A este respecto, durante el análisis, se encontraron contradicciones internas entre las ilustraciones y su pie de figura. En uno de los libros se encontró una imagen que tiene como pie de figura "Fauna de Gondwana al final de la Era Paleozoica". La ilustración contiene varios dinosaurios (Iguanodon, Bra- chiosaurus, Triceratops, Polacanthus, etc.) pero, durante la Era Paleozoica no existe registro fósil de estos géneros (ni de ningún otro dinosaurio), perteneciendo todos los organismos de la ilustración a la era Mesozoica. Este tipo de contradicciones en las etiquetas verbales fue también citado por Da Silva y Compiani (2006) en su trabajo sobre imágenes geológicas y geocientíficas en libros didácticos de ciencias en Brasil.

Contenido científico: imágenes e ideas alternativas

Se localizaron ideas alternativas en ciertas imágenes, en concreto reconstrucciones paleoecológicas que -sin hacer referencia a ningún periodo geológico en concreto-, representan una fau-

\section{Cuadro V}

Número de imágenes sobre dinosaurios según el tipo de etiqueta verbal $(\mathbf{n}=134)$

\begin{tabular}{lccc}
\hline & \multicolumn{3}{c}{ Etiqueta verbal } \\
\cline { 2 - 4 } & Sin Etiqueta & Nominativa & Relacional \\
\hline Número de imágenes & 26 & 91 & 17 \\
\hline
\end{tabular}

Fuente: Elaboración propia 
na compuesta por dinosaurios y otros animales coetáneos como reptiles voladores, reptiles marinos y mamíferos primitivos. En alguno de los ejemplos, el pie de figura vinculado a la imagen expone: "Los dinosaurios colonizaron todos los ambientes, terrestres, aéreos y acuáticos, y adquirieron gran variedad de formas" lanzando un modelo alternativo ya que los representantes del grupo de los dinosaurios fueron animales terrestres (a excepción de las aves que, filogenéticamente, deben ser consideradas el resultado de la evolución de dinosaurios terópodos y, por tanto, ser tratadas como 'dinosaurios' avianos).

No obstante la afirmación resulta, sólo en parte, premonitoria dado que recientes estudios científicos sobre los restos del dinosaurio terópodo Spinosaurus (Ibrahim et al., 2014) indican una posible adaptación al medio acuático (nunca antes referida para dinosaurios). A pesar de todo, las especies voladoras y acuáticas a las que se refiere no pueden ser clasificadas entre los dinosaurios (el pie de figura no diferencia qué animales representados en la imagen son dinosaurios). Así, el alumno puede pensar que reptiles marinos, reptiles voladores y mamíferos primitivos (entre los vertebrados representados) son dinosaurios, aunque no pertenecen (ni pueden ser clasificados) dentro de dicho grupo.

En otras imágenes análogas (carentes de etiquetas verbales en el interior de la figura) el pie de figura acompañante contiene información del tipo "Los dinosaurios dominaron nuestro planeta hace millones de años, pero por causas aun no aclaradas desaparecieron dejando sólo restos fósiles". En un sentido estricto no podemos decir que se incluya ningún modelo alternativo en la imagen, pero en el texto no se aclaran los contenidos presentados de ningún modo. $\mathrm{A}$ través de la "lectura" de la misma (y su pie de figura), se puede llegar a concluir que los dinosaurios (itodos los animales que aparecen en la imagen pertenezcan o no al grupo?) dominaron nuestro planeta hace millones de años.

La idea alternativa de atribuir hábitos aéreos y/o acuáticos a algunos dinosaurios, está asociada frecuentemente a la clasificación de "reptiles voladores" y "reptiles marinos" entre las filas de los dinosaurios. Este modelo alternativo también fue detectado al analizar los contenidos existentes sobre el concepto dinosaurio en Internet (Mampel y Cortés, 2009).

La polisemia de las imágenes y la superficialidad con que las observamos, salvo que haya razones que nos obliguen a una inspección más rigurosa, plantean la necesidad de dirigir con cuidado su interpretación mediante el uso de palabras (Perales y Jiménez, 2002). En el caso de los libros de texto analizados, o bien no existen dichas palabras (texto) o, cuando aparecen, no son capaces de encauzar la información para dotar de sentido completo a las imágenes.

Tipologías de contenidos en los libros e imágenes asociadas

La distribución de imágenes según las categorías: A) en el marco de las ex- 
tinciones y/o catástrofes, B) de forma descriptiva dentro de la historia de la Tierra y la Vida y C) con carácter anecdótico, establecidas según el modo de presentar la información sobre el concepto "dinosaurio" en Mampel y Cortés (2012), reveló una baja presencia de imágenes $(\mathrm{n}=23 ; 17,2 \%$ del total $)$ vinculadas a los libros con una tipología A ( $\mathrm{n}=14)$.

Los libros de texto pertenecientes a la categoría $B(n=17)$ incluyen un elevado número de imágenes sobre el concepto ( $\mathrm{n}=91$, que representan el $68 \%$ del total), con una media superior a 5 por libro analizado, así como el mayor número de imágenes con relaciones de tipo denotativo y sinóptico. Los libros de esta tipología también ilustran sus páginas -con mayor frecuencia- con ejemplos de Archaeopteryx (una prueba de evolución paleontológica bien conocida por alumnos de Bachillerato frecuentemente empleada para ejemplificar rasgos compartidos entre aves y dinosaurios; Puig y Jiménez Aleixandre, 2009) e incluyen, asimismo, el mayor porcentaje de reconstrucciones paleoecológicas (Cuadro VI).

Finalmente los 11 libros englobados bajo la categoría $\mathrm{C}$ incluyen un menor número de imágenes relacionadas $(\mathrm{n}=20,14,8 \%$ del total), con un índice número de imágenes por libros muy similar a la categoría A (Cuadro VI).

\section{Cuadro VI}

Tipología de libros de textos propuesta y tipo de imágenes asociadas

\begin{tabular}{|c|c|c|c|}
\hline & $\begin{array}{c}\text { EXTINCIÓN } \\
\text { A }(\mathbf{n}=14)\end{array}$ & $\begin{array}{c}\text { DESCRIPTIVO } \\
\text { B }(n=17)\end{array}$ & $\begin{array}{c}\text { ANECDÓTICO } \\
\text { C }(\mathbf{n}=11)\end{array}$ \\
\hline Ausencia Archaeopteryx & 11 & 5 & 5 \\
\hline \multicolumn{4}{|l|}{ Presencia } \\
\hline Archaeopteryx & 3 & 12 & 6 \\
\hline Índice ( $\mathrm{n}^{\mathrm{o}}$ imagen $/ \mathrm{n}^{\circ}$ libro) & 1,6 & 5,3 & 1,8 \\
\hline $\begin{array}{l}\text { Presencia reconstrucciones } \\
\text { paleoecológicas }\end{array}$ & $6(42,8 \%)$ & $12(70,5 \%)$ & $2(18,2 \%)$ \\
\hline $\begin{array}{l}\text { Presencia reconstrucciones } \\
\text { paleobiológicas }\end{array}$ & $4(28,6 \%)$ & $10(58,8 \%)$ & $5(45,45 \%)$ \\
\hline Connotativa & 17 & 78 & 16 \\
\hline Denotativa & 6 & 10 & 3 \\
\hline Sinóptica & 0 & 3 & 1 \\
\hline No Total Imágenes & 23 & 91 & 20 \\
\hline
\end{tabular}

Fuente: Elaboración propia 
Finalmente, independientemente de la categoría en la cual estén vinculadas las imágenes, el tipo de relación entre información visual e información textual más frecuente es asociativo (connotativo) con escasas referencias existentes entre imágenes y texto.

\section{Conclusiones y perspectivas}

El análisis de las imágenes sobre el concepto "dinosaurio" se efectuó a partir de una selección previa de 42 libros de texto del periodo LOGSE-LOE (19902010) que contiene información textual sobre el concepto (Mampel y Cortés, 2012). El 90\% de esta selección contiene un importante número de imágenes sobre dinosaurios -en total 134 , con una media superior a 3 imágenes por libro de texto- con una presencia destacada en libros de $4^{\circ}$ de ESO.

A pesar de la popularidad y el grado de interés científico que despierta el concepto "dinosaurio" no forma parte explícita del saber a enseñar. A pesar de ello, algunos autores y editoriales deciden incluirlo como objeto de ense$\tilde{n} a n z a$ en sus libros de texto donde se encuentra abundante información gráfica con un elevado grado de iconicidad, especialmente fotografías y modelos (tanto reconstrucciones paleobiológicas como paleoecológicas).

El análisis de las imágenes sobre el concepto reveló un claro predominio de relaciones de tipo connotativo entre texto e imágenes, donde queda en manos del lector usuario la tarea de establecer los posibles vínculos existentes.
El predominio de relaciones connotativas entre imágenes y texto, junto al uso de etiquetas nominativas (las más empleadas en este análisis), es coherente con la idea de que, cuanto mayor es la iconicidad de una imagen, menos explicaciones se requieren para su comprensión.

El papel de las imágenes sobre dinosaurios, en algunos de los libros de texto analizados, es decorativo o simplemente redundante, donde son menos importantes que el texto. En otros casos -especialmente en el caso de las reconstrucciones paleoecológicas-, poseen un gran volumen de información implícita donde la figura "desborda" al texto. En cualquier caso apenas se encuentran rasgos que identifiquen los elementos representados en cualquiera de las imágenes.

En general se observa una deficiencia en la concurrencia entre textos e imágenes que reduce el valor didáctico (y la eficacia) de las imágenes incorporadas. Sin un diseño apropiado y una consideración hacia el tipo de lectores, las imágenes pueden no ser mejores que el texto escrito sólo y, a lo peor, pueden actuar interfiriendo con el aprendizaje o incluso ser punto de partida de ideas alternativas. De hecho en el presente análisis se localizaron, de modo puntual, imágenes vinculadas con modelos (científicos) alternativos.

En relación con las reconstrucciones paleoecológicas y paleobiológicas se detecta la ausencia total de explicaciones o apuntes acerca de la metodología que permite llevarlas a cabo o cómo pueden 
variar conforme se avanza en el conocimiento científico. La función de los modelos es constituir un medio de representación del conocimiento a través del proceso de modelización, por lo que debiera potenciarse su uso teniendo presente la separación entre los planos real, teórico y simbólico. Tras el análisis puede concluirse que, en el caso de las reconstrucciones paleoecológicas, tal separación entre planos resulta inexistente.

Destaca la presencia de imágenes sobre las primeras aves fósiles -y de forma concreta la figura de Archaeopteryx - como ejemplo de evidencia paleontológica que respalda la teoría de la evolución. No se puede despreciar la importancia y potencial que tiene éste y otros conceptos paleontológicos relacionados en la construcción del conocimiento científico referente a esta controvertida teoría. Para realizar una lectura completa de la imagen de $A r$ chaeopteryx, los usuarios de los libros de texto deben tener conocimientos sobre qué es un dinosaurio (y qué no lo es) y qué es un ave. Pero el concepto "dinosaurio" apenas aparece en los textos de EP, irrumpiendo en ESO (Mampel y Cortés, 2012).

Sin la ayuda del profesor/a, puede constituir una exigente tarea para el alumno/a interpretar correctamente, y de forma autónoma, la imagen de $A r$ chaeopteryx como prueba paleontológica que respalda la evolución de las especies. A pesar de que conceptos como dinosaurio y ave pueden considerarse conceptos clave necesarios para entender la teoría de la evolución, ejemplificada con casos como Archaeopteryx (incluido en el 50\% de los libros analizados), la enseñanza de conocimientos científicos como datos, sin significado para los alumnos, puede convertir el aprendizaje de la ciencia en una cuestión de fe.

Los conceptos constituyen una parte básica de la ciencia, encargada de crear conceptos, definir términos y agruparlos en teorías. Para llegar a comprender los contenidos más abstractos y generales de una materia (como la teoría de la evolución) es necesario conocer previamente los contenidos más específicos, los conceptos y algunos datos (Pozo y Gómez, 1998).

Pedrinaci (1993) señalaba el valor didáctico del concepto "dinosaurio" y cómo debería aprovecharse para constituir una vía favorable en la transmisión de principios científicos generales, así como de conceptos de difícil asimilación, como el tiempo geológico necesario para establecer los rudimentos de las Ciencias Geológicas.

Como propuesta didáctica, se recomienda armonizar los contenidos de EP y ESO (especialmente en el caso de las editoriales que deciden incluir el concepto en ESO) de forma que se introduzca, de forma secuencial, algunos aspectos mínimos sobre el concepto "dinosaurio". Los dinosaurios suelen suscitar una gran expectación en alumnos desde los primeros niveles de enseñanza y se recomienda introducirlos de forma sucinta, como vía para descubrir el significado de las especies pretéritas ya extinguidas. Posteriormente, en la secuencia didáctica se puede incluir la 
definición de dinosaurio (por ejemplo en relación con la sección destinada a reptiles) y ave, para acabar incluyendo, en los últimos cursos de ESO, figuras de Archaeopteryx para explicar algunos aspectos de la teoría de la evolución de las especies, una vez asumidas las bases previas, o los cambios sufridos en los ecosistemas terrestres a lo largo del tiempo geológico (a través del uso y explicación de modelos como las reconstrucciones paleobiológicas y paleoecológicas). A través de la célebre extinción de finales del Cretácico se pueden tratar los efectos de una extinción global sobre la fauna y flora en general (y el caso de los dinosaurios en particular), reflexionando sobre el vínculo existente entre las aves actuales y los dinosaurios a través de ejemplos como Archaeopteryx.

\section{Referencias bibliográficas}

ALCALÁ, L. (2005). Trabajar con dinosaurios. Alambique. Didáctica de las Ciencias Experimentales, vol. 44, 57-65.

A N GLIN, G.J., VAEZ, H. y CUNNIGHAM, K.L. (2004). Visual representations and learning: the role of static and animated graphics. En: D.H. Jonassen (ed.). Handbook of research for educational communications and technology (865-916). Mahwah, New Jersey: Erlbaum.

BERMUDEZ, G. DE LONGHI, A., DÍAZ, S. y GAVIDIA, V. (2014). La transposición del concepto de diver- sidad biológica. Un estudio sobre los libros de texto en la educación secundaria española. Enseñanza de las Ciencias, vol. 32 (3), 285-302.

CALVO, J.M. y GIL-BAZÁN, E. (1997). Consideraciones sobre la didáctica de las reconstrucciones paleoecológicas y su problemática en la Educación Secundaria. Geogaceta, vol. 21, 47-49.

CAMPANARIO, J.M. (2001). ¿Qué puede hacer un profesor como tú o un alumno como el tuyo con un libro de texto como éste? Una relación de actividades poco convencionales. Enseñanza de las Ciencias, vol. 19 (3), 351-364.

CHEVALLARD,Y.(1985).Transposition didactique: du savoir savant au savoir enseigné. Grenoble. Francia: La Pensée Sauvage.

COOK, M.P. (2006). Visual representations in Science Education: the influence of prior knowledge and cognitive load theory on instructional design principles. Science Education, vol. 90 (6), 1073-1091.

COOK, M.P. (2008). Students' comprehension of science concepts depicted in textbook illustrations. Eletronic Journal of Science Education, vol. 12 (1), 1-14.

DA SILVA, F.K.M. Y COMPIANI, M. (2006). Las imágenes geológicas y geocientíficas en libros didácticos de ciencias. Investigación didáctica. Enseñanza de las Ciencias, vol. 24 (2), 207-218. 
DE DIOS, J., HOCES, R. y PERALES, F.J. (1997). Análisis de los modelos y los grafismos utilizados en los libros de texto. Alambique (versión electrónica), 11, $6 \mathrm{p}$.

DIMOPOULOS, K., KOULAIDIS, V. y SKLAVENITI, S. (2003). Towards and analysis of visual images in School Science Textbooks and press articles about Science and Technology. Research in Science Education, vol. 33, 189-216.

FANARO, M., OTERO, M.R. y GRECA, I. (2005). Las imágenes en los materiales educativos: las ideas de los profesores. Revista Electrónica de Enseñanza de las Ciencias, vol. 4 (2), 1579-1513.

GARCÍA-CARMONA, A. (2014) Naturaleza de la ciencia en noticias científicas de la prensa: análisis del contenido y potencialidades didácticas. Enseñanza de las Ciencias, vol. 32 (3), p. 493-509. http://dx.doi.org/10.5565/ rev/ensciencias.1307 [Consultado 6 Noviembre 2014]

GÍL QUÍLEZ, M.J. y MARTÍNEZ PEÑA, M.B. (2005). El modelo SolTierra-Luna en el lenguaje iconográfico de estudiantes de magisterio. Investigación didáctica. Enseñanza de las Ciencias, vol. 23 (2), 153-166.

GIL-BAZÁN, E. (2009). La paleontología en la Educación Secundaria aragonesa. Naturaleza Aragonesa, 22 (enero-junio 2009), 4-8.

GÓMEZ, R. y VALBUENA, R. (2008). Conocimiento del Medio 4. Aragón.
Primaria-Segundo Ciclo. Abre la Puerta. Grupo Anaya.

GÓMEZ, R., VALBUENA, R. y BROTONS, J.R. (2007). Conocimiento del Medio 5. Aragón. Primaria-Segundo Ciclo. Abre la Puerta. Grupo Anaya.

IBRAHIM, N., SERENO, P.C., DAL SASSO, D., MAGANUCO, S., FABBRI, M., MARTILL, D.M., ZOUHRI, S., MYHRVOLD, N. y IURINO, D.A. (2014). Semiaquatic adaptations in a giant predatory dinosaur. Science. DOI: 10.1126/ science. 1258750.

IZQUIERDO, M., MÁRQUEZ, C. y GOUVEA, G. (2008). A Proposal for Textbooks Analysis: Rhetorical Structures. Science Education International, vol. 19 (2), 209-218.

JIMÉNEZ, J.D. y PERALES, F.J. (2001). Aplicación del análisis secuencial al estudio del texto escrito e ilustraciones de los libros de física y química de la ESO. Enseñanza de las Ciencias, vol. 19 (1), 3-19.

LEVIE, W. y LENTZ, R. (1982). Effects of text illustrations: A review. Research Educational Communications and Technology Journal, vol. 30, 195-232.

MAMPEL, L. y CORTÉS-GRACIA, A.L. (2009). Los motores de búsqueda de información en Internet como herramienta de aprendizaje: análisis de contenidos sobre el concepto "dinosaurio". Revista Electrónica de Enseñanza de las Ciencias, vol. 8 (3), 770-796. 
MAMPEL, L. y CORTÉS-GRACIA, A.L. (2012). El concepto 'dinosaurio' en los libros de texto. Enseñanza de las Ciencias de la Tierra, vol. 20 (3), 239248.

MAMPEL, L., ESPÍLEZ, E., LORENTE, M., FABRE, J. y ALCALÁ, L. (2011). Domus: un reto hacia la adaptación de colecciones paleontológicas. Paleontología i evolució. En: J. Marigó, M. Pérez, R. Minwer-Barakat, D. De Miguel y A. Bolet (Eds.). XXVII Jornadas de la Sociedad Española de Paleontología. Memoria especial 5, 211-214.

MATUS, L., BENARROCH, A. y PERALES, F.J. (2008). Las imágenes sobre enlace químico usadas en los libros de texto de educación secundaria. Análisis desde los resultados de la investigación educativa. Enseñanza de las Ciencias, vol. 26 (2), 153-176.

MAYER, R. E., STEINHOFF, K., BOWER, G. y MARS, R. (1995). A generative theory of textbook design: usingannotatedillustrations to foster meaningful learning of science text. Educational Technology Research \& Development, vol. 43 (1), 31-43.

MOLES, A. (1991). Pensar en línea, pensar en superficie. En: J. Costa y A. Moles (eds.). Imagen Didáctica. Enciclopedia del Diseño. Barcelona: CEAC.

MOTTET, G. (1996). Images et activités scientifiques. Reintegrer l'image. Aster, vol. 22, 3-13.
NAJJAR, L. J. (1995). Dual coding as a possible explanation for the effects of multimedia on learning. Technical Report. School of Psychology and Graphics, Visualization, and Usability Laboratory, $11 \mathrm{p}$.

OTERO, M.R., GRECA, I.M. y DA SILVEIRA, F.L. (2003). Imágenes visuales en el aula y rendimiento escolar en Física: Un estudio comparativo. Revista Electrónica de Enseñanza de las Ciencias, vol. 2 (1), 1-30.

PAIVIO, A. (1986). Mental representations: a dual coding approach. New York: Oxford University Press.

PARDO, P. y REBOLLO, L.F. (2008). Análisis de libros de texto de geología. Aplicación al ciclo del agua en ESO. Enseñanza de las Ciencias de la Tierra, vol. 16 (1), 79-91.

PEDRINACI, E. (1993). La construcción histórica del concepto de tiempo geológico. Enseñanza de las Ciencias, vol. 11 (3), 315-323.

PERALES, F.J. (2006). Uso (y abuso) de la imagen en la enseñanza de las ciencias. Investigación Didáctica. Enseñanza de las Ciencias, vol. 24 (1), 13-30.

PERALES, F.J. (2008). La imagen en la Enseñanza de las Ciencias: algunos resultados de investigación en la Universidad de Granada, España. Formación Universitaria, vol. 1 (4), 13-22.

PERALES, F.J. y JIMÉNEZ, J.D. (2002). Las ilustraciones en la enseñanzaaprendizaje de las ciencias. Análi- 
sis de libros de texto. Investigación didáctica. Enseñanza de las Ciencias, vol. 20 (3), 369-386.

PERALES, F.J. y JIMÉNEZ, J.D. (2004) Las ilustraciones en los libros de Física y Química de la ESO. En: J.J. Gil (Coord.), Aspectos didácticos de Física y Química. I.C.E. de la Universidad de Zaragoza.

PERALES, F.J. y VÍLCHEZ-GONZÁLEZ, J.M. (2012). Libros de texto: ni contigo ni sin ti tienen mis males remedio. Alambique, vol. 70, 75-82.

PÉREZ DE EULATE, L., LLORENTE, E. y ANDRIEU, A. (1999). Las imágenes de digestión y excreción en los textos de Primaria. Investigación didáctica. Enseñanza de las Ciencias, vol. 17 (2), 165-178.

POZO, J.I. y GÓMEZ CRESPO, M.A. (1998). Aprender y enseñar ciencia. Madrid: Morata.

PUIG, B. y JIMÉNEZ ALEIXANDRE, $M^{a}$.P. (2009). ¿Qué considera el alumnado que son pruebas de la evolución? Alambique. Didáctica de las Ciencias Experimentales, vol. 62, 43-50.

REID, D. (1990a). The role of pictures in learning biology: Part 1, perception and observation. Journal of Biological Education, vol. 3 (24), 161-172.
REID, D. (1990b). The role of pictures in learning biology: Part 2, picture-text processing. Journal of Biological Education, vol. 4 (24), 251-258.

REYNOLDS, S.J., JOHNSON, J.K., PIBURN, M.D., LEEDY, D.E., A COYAN, J. y BUSCH, M.M. (2005). Visualization in undergraduate Geology courses. En: J.K. Gilbert (ed.), Visualization in Science Education, 253-266.

ROMERO NIETO, D., FESHARAKI, O. y GARCÍA YELO, B.A. (2014). Películas de trasfondo paleontológico: análisis científico y propuestas didácticas. Enseñanza de las Ciencias de la Tierra, vol. 22 (2), 167-176.

SILVA, F.K. y COMPIANI, M. (2006). Las imágenes geológicas y geocientíficas en libros didácticos de ciencias. Enseñanza de las Ciencias, vol. 24 (2), 207-218.

TORCIDA, F. (2003). Didáctica sobre Dinosaurios en museos y centros educativos; experiencias desarrolladas en España. En: F. Pérez-Lorente, M. Romero y P. Rivas (coord.) Dinosaurios y otros reptiles mesozoicos en España. Congreso Internacional sobre Dinosaurios y otros Reptiles Mesozoicos en España. Memoria especial 5, 423-432.

VERRET, M. (1975) Le temps des études. París: Librarie Honoré Champion. 
